\title{
Cultural, Institutional, And Economic Factors Inhibiting The Transition From Tobacco Cultivation To Alternative Forms Of Agriculture In South Central Appalachia
}

Donald J. Shemwell, (E-mail: shemweld@etsu.edu), East Tennessee State University

\begin{abstract}
A series of preliminary investigations indicated the strong need for alternatives for tobacco farming. Progressive elements in the communities where the study took place often suggested that this particular economic development issue should be a leading or critical priority. Nevertheless, when the issue was put to communities at large in subsequent community sustainability studies, there was little enthusiasm among the populace for alternative agriculture initiatives. The study reported here involved interviews with thirteen tobacco growers, two intermediaries who have grown tobacco themselves and worked among the farmers for many years, and representatives of three entities that have demonstrated success in alternate methods. The results indicate that there are substantial institutional, economic, and psychological barriers to grower adaption. The most important institutional barriers are the concentration in retailing and the development of highly centralized buying offices. The most significant economic barriers are the high start-up costs and variable nature of returns. Finally, the most salient cultural barrier is a learned helplessness resulting from years of isolation from market forces and an under educated and aging populace in farm communities.
\end{abstract}

\section{Introduction}

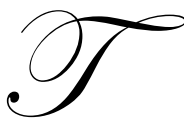

he principal investigator is a marketing professor at an AACSB accredited regional university that has as part of its mission a regionally-based service orientation. Tobacco has always been the area's biggest cash crop. It remains so today even after the allotment cuts of the late nineties.

A significant source of funding for the community service initiatives the university undertook was a grant from the Kellogg foundation. Early rounds of funding were used by the university' s medical school to build health clinics and other basic services. Often the university's clinics provided the only local alternative to area residents. As later rounds of funding provided support for economic development the business college got involved through the principal investigator in this study and several other progressive professors. As part of the needs analysis process the principal investigator, his colleagues, professors from hard sciences, attended numerous meetings in area communities. The bureaucrat who controlled the funding called them New Century Councils.

New century council meetings were attended by a small but loyal cadre of community representatives. Generally, these people were very progressive and enthusiastic. While we knew that these people were more highly educated, more successful, more optimistic, and more adaptable than the community at large. We believedwrongly as it turned out — that their sentiments were representative of the broader populace.

Readers with comments or questions are encouraged to contact the author via email. 


\section{Background}

In New Century Council meetings people invariably indicated that they saw the development of alternative agricultural opportunities as a critical (and in many cases the critical) economic development issue that faced the community. During the time that we were attending the meeting the first big allotment cut occurred with the average allotment being halved (for an explanation of how allotments work see Department of Agriculture). The following anecdote provides a vivid illustration of their expressed need. The trend continued in 2002, with allotments being cut again somewhere between $25 \%$ and $42 \%$ depending on the type of tobacco (Tobacco Farmer 2002).

Some colleagues and I were at a New Century Council Meeting in the county where the first preliminary study took place. The county executive was talking about some traditional economic development related to downtown revitalization. A lady raised her hand, waited patiently for acknowledgment, and said. "Everyone in my family grows tobacco. I grow tobacco. Everybody I know grows tobacco. It's becoming obvious that there is no future (in tobacco). We need to find some way to replace tobacco with other crops."

The allotment system has evolved over the years to a scheme whereby there is only one seller and fluctuations between supply and demand are buffered by taking the excess supply and warehousing it for later sale and use (Jones 2002, p. 4). Tobacco can be safely warehoused for several years, so this process works pretty well in the short run. Excess production can only be shielded for so long before production has to be cut. Most allotments in the area in which the study took place are fairly small (less than 5 acres) in size and the profits, while higher than other crops on a per-acre basis, are small in total. One informant said (and the others agreed during the validity check process) that "95 percent of the farmers net less than $\$ 25,000$ a crop."

The next year (after the first big allotment cut) another cut of close to 50 percent was instituted leaving many farmers in the area with an allotment of just a quarter of what it was two years previous. It seemed that the development of alternatives to tobacco would be the logical cornerstone to the university's efforts to help provide support for community sustainability efforts in the rural areas of the region.

\section{Earlier Studies}

It was at this time that a sustainability study was conducted in a rural county in South Central Appalachia. The scale points of the sustainability questions were set up in bi-polar fashion with Very Harmful and Very Beneficial as the anchors. The exact scale points were Very Beneficial, Beneficial, Slightly Beneficial, Not Sure, Slightly Harmful, Harmful, and Very Harmful. The purpose of this was to allow the researchers to speak in terms of support (or opposition) to concrete actions.

The second page of the questionnaire contained demographic items and some open ended questions. Typical demographic items such as age, gender, education, number in household, and years lived in the county were augmented by questions about connectedness and the respondent's personal interest in activism.

The survey was designed to be short and ended up fitting on one sheet of paper (front and back). It was then mailed to the entire population of interest. Two-hundred thirty-four responses were received (see the section titled "Descriptive Statistics") for an approximate response rate of $15 \%$. Not surprisingly in a mail study conducted in a poor rural county with low literacy and educational attainment rates, comparison of demographic data to existing information revealed a slightly more educated, female and upscale respondent, but not dramatically so.

The second of the two sustainability studies was done about a year later in another non-contiguous rural county in the South Central Appalachian region. Students in a sales class called approximately 1200 county residents with even numbered phone numbers to get 800 people to agree to fill out the survey. Another 476 people with phone numbers ending in $9 \mathrm{~s}$ received another copy of the same survey. This second group represents a random sample of households with phones. A MANOVA analysis found no significant differences in survey responses between respondents who had agreed over the phone to fill out the survey and the blind mail respondents, so those two data sets could then be pooled. 
Both studies were conducted for the purpose of furthering community sustainability in the areas studied. Thus, the researchers were looking not for a majority of favorable opinions, but for areas of strong consensi to serve as the foci for efforts by the university. Surprisingly, the support for developing alternatives to tobacco was much weaker than anticipated. In both studies this action was in the bottom quarter. Only questions about encouraging diversity and zoning were consistently ranked lower. The study described below is designed to answer the questions posed by the counter intuitive findings of the first two studies.

\section{Method}

Three sets of informants were interviewed, tobacco farmers, intermediaries, and successful developers of alternative crops. Each farmer was interviewed in a social setting for approximately an hour. The intermediaries were asked to conduct their own investigation among the farmers they knew and report back on what they had discovered. They served as something in between second level respondents and expert informants. The other participants were people who had developed alternative-crop models. This last group was not interviewed per se, but agreed to provide access to the principle investigator, his students, and interested farmers. The principal investigator had supervised internships and conducted or supervised studies and had extensive experience with these entities and intimate knowledge of the economics of their operations. One alternative model was an organic growers cooperative. Another was a hydroponic farming demonstration project which grew first tomatoes and then bib lettuce. The final participant was a successful vineyard operator and head of an area grape growers association. These alternatives were discussed with the farmers as part of the interview process.

\section{Results and Discussion}

The process of taking interview data and categorizing it to supportable central conclusions is always subject to some interpretative variance. Some anecdotes stick out and others are forgotten. Certain threads may not have been followed with the same zeal as others. Nevertheless, the data gathered from the interviews with farmers point directly to two broad geni of causes for the lack of enthusiasm among the tobacco growing community for developing alternative crops and indirectly at a third. The data derived from the resellers recognize the former causes and point directly at the third genus.

\section{Institutional Reasons for Grower Maladaptiveness}

The structure of the markets for produce and other crops has changed dramatically. Several factors have combined to marginalize (even further) the small producer. Grocery retailing has seen massive concentration over the last few decades. The smaller mom and pop stores and even localized chains have been out competed by larger multi-state and national chains. Local stores have traditionally supported local producers. Their replacement by large-scale chains who have little commitment to the communities they serve has really hurt market access by family scale farmers. A related problem is that the buying process has become much more centralized and sophisticated. These centralized purchasing operations have little interest in the small-scale wholesalers who provide a safety net market for small producers. Even those retailers that do empathize with the family farmers have become so dependent on electronic data processing that they experience terrible inventory control problems if they offer a local alternative. Aggravating this situation even further is the recent vendor-streamlining fad. For example, Kmart made a deal to buy all its groceries from a single vendor in the months preceding its bankruptcy. While this kind of arrangement may result in short run savings for grocers like Kmart, it has very scary implications for small-scale farmers and wholesalers.

Another institutional change affecting small-scale farmers is that there have been vast improvements in the speed and efficiency of shipping systems. The widespread adoption of containerized freight hauling and the cost savings associated with these improvements mean that large amounts of fruit and other products can be moved vast distances at minimal costs. Technological improvements such as hydro-chillers make it easier to preserve a cosmetically perfect product longer during shipping and on the shelf. While the modern consumer is now able to eat their favorite fruit and vegetables year round in many cases, these changes have had significant negative impacts on small-scale producers and wholesalers who have historically marketed locally. 


\section{Economic Reasons Given}

Alternative products have been shown to be successful and demonstration facilities are readily accessible to tobacco farmers. In addition to the larger scale facility whose manager served as an informant, high schools in both counties studied earlier have hydroponic operations and teach the technology to future generations. The members of the grape growers association have been able to sell all their grapes to vineyards in the local area, and several wineries are well on the way to developing reputations for making excellent wines. The local organic farmers association is now selling to over 100 stores in the wider region.

Nevertheless, all of these operations require significant up-front investments. Grape vines do not produce until the third year and it takes about eight years to reach real maturity. Hydroponic farming requires several hundred thousand dollars for a one acre operation. Smaller scale facilities can be started at a much smaller scale, but still require significant investment. Most states require farmers to keep their farms free of chemical pesticides and fertilizers before the product can be certified organic. The problem is that variable returns to an significant up-front investment just does not go over well with people who are used to growing a guaranteed sale product at a stable price with disaster relief and other support thrown in.

\section{Cultural Reasons Given}

The final problem is that the culture just does not support adaptiveness to change (Jones 2002, p. 17-18). It may be a surprise to many, but farming is a very speculative endeavor. One wholesaler related an anecdote about two small scale $(5$ acre) tomato farmers who existed side by side. The one started his crop at the perfect time and got his crop to market during a lull. He got doubly lucky when his second picking hit at a rare summer weak spot. The other farmer was about two and half-weeks behind in his first picking and hit a terrible glut. He never even got a second picking as the prices were too low to justify paying pickers. The first farmer made a $\$ 100,000$ profit and the second lost money even though their production was nearly equivalent.

Many of the farmers are older, illiterate or barely literate and have little taste for being speculators and businessmen. Years of cropping a guaranteed product have created a kind of learned helplessness. A constant refrain was "we need the government to back it," or "If the government would back it, I would be interested."

Finally, there was a lot of resistance to any kind of change. Many farmers indicated that they did not feel capable of learning new ways to farm. Organic farming for instance can be very frustrating for people who have solved every mold, insect or pest problem by spraying pesticides. It takes lot of patience to develop natural fertilizers. The technology used for hydroponic farming may seem bewildering to an older person who has farmed the same way all his or her life.

\section{Limitations and Future Research}

This study was conducted in South Central Appalachia and may not generalize to other areas. The area is hilly and mountainous and most farms are small in size (very small compared to the California or the Midwest). The people are very unique and the counties studied may not be representative of the region. The study was exploratory in nature and it would be interesting to see more sophisticated and broader studies.

\section{Conclusion}

It is not easy to answer to the problem of how to compensate tobacco farmers for the loss of their livelihood due to increased foreign production and rules, regulations, and taxes. Certainly tobacco is an unhealthy and dangerous product. Its decline is (hopefully) inevitable. Unfortunately the studies described here do not provide an answer. Some of the tobacco settlement money has been distributed to growers as compensation, but while laudable one time cash distributions are a poor substitute for a 75 percent allotment cut. Our efforts at this university have focused on the "give a people some fish and they will eat for a night; teach them to fish and they will eat for many 
generations" metaphor. The efforts contained herein provide no answers, but perhaps providing a clearer understanding of the problem will help others find solutions.

\section{References}

1. Tobacco Farmer (2002), Unattributed, http://www.tobaccofarmer.com/current/bf0402/flyings.asp.

2. Department of Agriculture (2002),

http://www.access.gpo.gov/nara/cfr/cfrhtml_00/Title_7/7cfr723_main_00.html

3. Jones, Alan Michael (2002), "Washington County Tobacco: The Status of Declining Tobacco Demand and the Adverse Affect on Farmers and the Economy," Unpublished Thesis.

Notes 
Notes 